\title{
GENTE VIVA. EXPERIENCIAS ACTIVISTAS SOBRE EL AMBIENTE Y LA MADRE TIERRA EN MÉXICO
}

\author{
José David Lara-González* \\ Benemérita Universidad Autónoma de Puebla, México
}

http://dx.doi.org/10.5209/rev_NOMA.2012.41771

\begin{abstract}
Resumen.- México se encuentra en una situación de crisis que se ha ido agudizando en las últimas décadas. Los problemas sociales ahora han crecido a problemas ambientales. Los gobiernos no han sido capaces de entender ni atender los agravados problemas de hoy. Los individuos y las sociedades han sido golpeados por estos problemas, la naturaleza también. Ante la falta de soluciones la gente ha creado movimientos propios y ha planteado sus posiciones. Mediante el levantamiento de encuestas directamente aplicadas a participantes y no participantes en diversos eventos de muy distintas magnitudes, se recopiló la presente información para testimoniar y hacer más conocidas las demandas, actitudes y propuestas de todas estas personas y agrupaciones, afectados ambientales y para dar a conocer, en forma resumida, las luchas democráticas que se están realizando en todo el país por la justicia ambiental. Igualmente se realiza una comparación con otros actores de otras luchas en el seno mexicano dadas a conocer por otros autores y procedimientos. Se observa que el capitalismo neoliberal es la razón de fondo del desequilibrio en el país y se observa que existe gente que genera una esperanza para una vida mejor, cercana a la sustentabilidad.
\end{abstract}

Palabras clave.- gobierno, crisis, luchas sociales, encuestas, neoliberalismo, resistencia civil.

\section{People alive. Activists experiences on the environment and Mother Earth in Mexico.}

\begin{abstract}
Mexico is in a critical situation that has become more acute in recent decades. Now social problems have grown to environmental problems. Governments have not been able to understand or address the compounded problems of today. Individuals and societies have been hit by these problems, the nature as well. In the absence of solutions people have created their own movements and raised positions. By collecting directly applied interviews to participants and non participants in events of very different magnitudes, the information was gathered to witness and make it known demands, attitudes and suggestions of all these people and groups who are environmental affected and to release in summary form, the democratic struggles that are taking place across the country for environmental justice. Likewise, a comparison with other actors in other struggles within the Mexican country released by other authors and procedures has made. It's noted that neoliberal capitalism is the real reason for the imbalance in the country and it's noted too that there are people that generates hope for a better life, closer to sustainability.
\end{abstract}

Keywords.- government, crisis, social struggles, interviews, neoliberalism, civil resistance.

\section{Introducción}

Hemos visto y participado en lo acontecido en nuestro mundo durante las últimas décadas. Así, hemos contemplado el desarrollo increíble de la tecnología y el 
avance tremendo de las ciencias, igualmente hemos sido testigos de la generación de la riqueza económica hasta niveles no presenciados antes. Sin embargo y en contraparte, también somos testigos de los terribles niveles de pobreza y miseria que azotan a millones de personas, estamos enterados de los desastres dados sobre muchos ecosistemas de mayor y menor tamaño, observamos con preocupación la problemática del cambio-calentamiento climático global, y somos partícipes del sistema y estado de crisis traslapadas e imbricadas que están impactando al orbe como jamás antes había sucedido y, con problemas tan serios que llegan a conformar distintas guerras alrededor del mundo (Klare, 2003).

Los medios masivos de información-comunicación haciendo uso de su alto poder, "bombardean" a las poblaciones con todo tipo de informaciones sobre lo mal que el mundo se encuentra. Hay una fuerte tendencia a mostrar los casos peores y a "explotar" los sucesos más nocivos y violentos para buscar penetrar en los públicos y asegurarse un "rating" elevado llegando hasta a "construir" los hechos para producir "montajes escénicos" que sustituyen a la realidad generando a la vez una sociedad teledirigida (Sartori, 2007).

El mundo necesita información y comunicación pero deben ser dadas en un ámbito de moral y ética no a modo para los intereses de las empresas que las poseen y distribuyen, tampoco para el de las empresas que las patrocinan y/o son sus asociadas, sino de moral y ética humanizadas, ambientalizadas que van a cumplir con verdaderas labores necesarias para las sociedades y para los individuos, sociedades e individuos sanos, no los que los modelos impuestos por el poder de los grupos glocales (globales y locales) dueños hegemónicos de las riquezas le han destinado a la humanidad y resto del mundo desde mucho tiempo atrás creando seres autómatas que de ser urbanitas terminan siendo unos urbanópatas (Torres, 2006), esclavos despilfarradores en demasiados casos y seres que se han ido deshumanizando sometidos a los tratamientos deformantes del sistema impuesto de vida donde no se puede vivir ya, tan solo sobrevivir dentro de amplios casos de injusticia.

Entonces, pensamos que es necesario enterarnos cuando menos un poco del otro perfil, es decir, de observar lo que miles o quizás millones de personas en México han estado viviendo y experimentando, también padeciendo y haciendo $\mathrm{y}$, nos damos a la labor de dejarles un "espacio" para hacer llegar sus voces y vivencias hasta otros hermanos y hermanas mexicanos y extranjeros dentro de un ejercicio que intenta la comunicación entre todos nosotros para buscar una conciliación y reconciliación nacional que sea más cercana a la sustentabilidad de la existencia, o sea, una existencia viva y ambientalizada.

\section{Aproximación metodológica}

Nos hemos dado a recopilar una pequeña muestra de las luchas contra el "leviatán sistema" para hacer patente el papel de las personas en esto y para dejar aunque una ligera huella de las actividades y acciones de las mimas, así como para darles una oportunidad de ser escuchadas tanto como para darnos una oportunidad de escuchar las voces de estas gentes preocupadas y ocupadas por la vida misma y 
el devenir inmediato y mediato del mundo y del país mexicano, recordando que sus luchas, esfuerzos y sufrimientos son la energía y materia que quiere brindarle a la Madre Tierra otra oportunidad para la vida, para sostener la vida, para abrigar la vida y dotarla a ella misma de vida, la propia vida que somos nosotros mismos.

Acudiendo a numerosos "encuentros" de todo tipo y magnitud efectuados en varias localidades del país en diferentes entidades federativas del mismo, en fechas de los últimos tres años, se efectuaron entrevistas abiertas a los participantes, desde los protagonistas hasta el público asistente pero igualmente se aprovechó para recabar el decir de otras personas NO participantes, es decir, gente que "solo pasaba por ahí" en el momento de tales encuentros y que no estaban enterados ni de las temáticas tratadas en ellos ni del hecho de la realización ni motivación-razón de los mismos.

Estamos tratando con "encuentros" como cursos, congresos, campamentos, festivales, talleres, conferencias, marchas, plantones, toma de calles y edificios, cierre de vías carreteras, reuniones, asambleas, huelgas de hambre y demás, sí, "encuentros" de muy variada naturaleza, "movimientos" en sí. "Eventos" políticos, organizativos, festivos, informadores, formadores, culturales, artísticos, tradicionales-costumbristas, de protesta, de conciliación-negociación, de diálogo, de propuesta y otros más. "Encuentros" desde meramente populares organizados para múltiples casos hasta otros convocados por instituciones oficiales de gobierno y de instancias educativas, sindicales, etc., pero igualmente eventos espontáneos dados por la premura de las distintas circunstancias y hechos. En ellos se cuenta la participación de políticos en funciones, miembros del gobierno, afectados ambientales directa e indirectamente, grupos de apoyo, simpatizantesempatizantes, patrocinadores, académicos, partidistas políticos y un gran grupo de gente del pueblo. Yendo la participación desde unos cuantos hasta la de cientos y miles en una sola vez.

Con mayores y menores logros de todos estos "encuentros" y "eventos" realizados bajo techo, al aire libre, en ambientes cerrados, en plazas y edificios públicos, en las ciudades y en el campo y con duración de unas horas o hasta varios días seguidos, daremos paso a las voces de los-as entrevistados-as para enterarnos un poco de sus palabras y como testimonio de unas vidas agitadas por los procesos de capitalización mundial de la globalización en marcha. Estamos manejando en este escrito al ambiente en su concepción como el sistema de interrelaciones entre los sistemas humanos y los sistemas propios de la naturaleza, de ahí el carácter de los ítems planteados a los-as entrevistados-as que contienen puntos tanto sociales como ecológicos o de la naturaleza.

Se complementa el presente trabajo mediante la incorporación de otras experiencias y voces provenientes de otros afectados y momentos cuya información ha sido captada por otros autores. Con ello intentamos un comparativo generalizado entre el ambiente dado dentro del "cosmos" por nosotros levantado directamente para referirlo a un marco mayor aportado por las condiciones de otras luchas socioambientales en el país y extendiéndonos a otros ítems de la problemática nacional. 


\section{Resultados y discusión}

A continuación aparecen los señalamientos que la gente hace acerca de cinco ítems levantados. Primero reproducimos, particularizando los ítems en cuestión, el decir de las personas involucradas en los muy distintos "encuentros", es decir, los convocantes-participantes-asistentes; después, de modo generalizado anotamos lo dicho por personas "no involucradas".

\section{Sobre el papel del gobierno mexicano en la situación del país:}

Yadira, joven estudiante de licenciatura universitaria nos dice: "si nosotros mismos no hacemos lo necesario el gobierno no tiene la capacidad ni la voluntad para sacarnos del infierno en que nos metió. Sólo busca nuestros votos hasta comprándolos y presionando todo el tiempo". Salvador, estudiante de secundaria pública contesta: "no conocemos al gobierno, no viene acá y no cumple con las promesas". Petronila, ama de casa de edad mediana afirma: "he votado muchas veces pero no veo los resultados del gobierno con la democracia, creo que la democracia está inventada, no hay justicia ni trabajo hay". Agustina, comerciante en pequeño metida al mercadeo de artículos "pirata" señala: "ya no espero que el gobierno cumpla, ya no voto ni voy a volver a votar. Que se vayan a otro país, no los queremos en México. El gobierno se pecha de nosotros, es pechón, se pecha hasta los votos siempre". Eduardo, maestro de educación media superior para el Estado nos indica: "nuestros gobernantes nadan en dinero y son corruptos, no trabajan y no saben lo que es ganarse el pan de cada día. Nosotros como lo dijo ese candidato a Presidente de México somos los invisibles. Yo trabajo para el gobierno pero me pagan con miseria y vivimos mal, no puedo llevar a mis hijos al doctor ni a una escuela más buena. Tengo estudios en la universidad pero no hay trabajo de eso". Mariana, señora ya en senectud, dedicada a atender un negocito de venta de revistas y periódicos responde: "no puedo dejar de trabajar, ya me canso mucho y no veo bien, me enfermo seguido, me duele la panza y la espalda seguido, con la cabeza se me va a caer. Del gobierno no le creo ni nada de nada. Vienen se llevan lo que pueden y se van. No dejan para nosotros ni un pedazo de nada. No tengo medicinas, como lo que se puede y siento que "la calaca" está cerquita, sí, jefe". Dolores, un señor de mediana edad campesino y obrero contesta: "yo solo quiero algo para mis hijos, dios me dio muchos hijos pero estamos quebrados, varios ya se fueron con los gringos, a ver si regresan, dejaron aquí sus niños. Nuestro gobierno no da trabajo, nadie da trabajo, tenemos que hacer nosotros mismos el trabajo pero ganamos poco y la tierra se va enflacando, no la dejamos descansar. Nuestra Pachamama (Madre Tierra) está cansada y vienen y encima le echan hartas porquerías y quieren que nos dé de comer. El gobierno no sabe, los ingenieros y los licenciados solo trabajan para el gobierno y nos engañan. El buen gobierno debería hacer algo para que no se vayan los hijos al extranjero y la Pachamama viva de nuevo bonito como en antes". Soria, muchacha ama de casa dice: "el Presidente es buena persona y está peleando 
contra los ricos para darnos algo de lo que ellos tienen mucho. Yo no sé de partidos ni de cosas políticas pero veo buen trabajo de este presidente. Tenemos a un rico más rico del mundo, así se entera la gente de qué somos los mexicanos". Josefina, miembro de un sindicato de una institución pública responde: "la lucha es por hacer un gobierno fuerte. Este gobierno y los otros van para atrás. Son amigos de los capitalistas y odian todo lo social y socialista. El papel del gobierno está para darle a los mexicanos, todas y todos, los derechos que nos pertenecen y están en la Constitución. Se olvidan de eso y por eso estoy en contra y estoy presente, dando la cara y haciendo mi parte con mucho gusto y para que mis hijos vean lo que podemos hacer en lugar de estar pegados a la tele haciendo nada con el tiempo". Fernando, muchacho ayudante de carnicero nos dijo: "la carne nos la limitan más y las señoras ya más poco la pueden comprar. El gobierno lo mismo te da que te quita pero quita más. Entran más perros que gente al negocio, hay muchos perros y nos echan la culpa pero no los atrapan y si los agarran los dejan después por ahí. La gente que trabaja en el gobierno es más floja, solo hacen que trabajan y no cumplen con el trabajo, mienten y engañan ¿quién le cree a los del gobierno?".

\section{Sobre el acoso de las empresas para adueñarse de los recursos por todo el país:}

Rolando, maduro campesino tlaxcalteca dice: "yo no dejaré de mi parte que se hagan propietarios de mi misma parte no más porque son los que tienen el dinero y compran al gobierno. Están aquí con sus grandes carros y nos "apantallan" con sus trajes caros y sus palabras desconocidas muchos licenciados y todo, pero no me engañan y yo les dejaré mis cosas a mi mujer y a mis hijos cuando me lleve dios con él". Juana, joven artesana del barro nos contestó: "ya estuvieron aquí en el pueblo para ofrecernos el pago de nuestro patrimonio. Primero me engañaron y les di mis papeles, ahora sé la verdad y no quiero venderles ni un pedazo de tierra. Exijo que me den mis papeles, además ni me pagaron un peso. Mi familia se quedará sin nada, entonces doy pelea ahora y no me van a hacer tonta otra vez, ya verán esos topos negros". Amado, albañil de edad moderada, dijo: "mis papás me dejaron lo que tengo y a mis hermanos, así tenemos unos cachitos de tierra, el suelo nos da y los ricos nos quitan. Nos amenazan con expropiar, otros vecinos ya vendieron pero se arrepienten. Yo tengo miedo del gobierno que nos obligue a venderle a las empresas que llegan seguido hasta aquí y, nos dicen que el gobierno está con ellas. Algunas de esas empresas de por sí ya están en la región y pagan bien poquito a sus trabajadores y echan harta contaminación y se quedan con el agua para el pueblo". Sebastiana, jornalera en el campo anota: "no entiendo para qué quieren todo, no se lo pueden comer, no se lo pueden llevar, para qué tienen que quedarse con todas nuestras cosas, para qué quieren hacerle daño a la tierra, la tierra es la madre y nosotros tenemos que darle algo a cambio. Ellos no le dan nada. Son envidiosos y les va a ir mal. Dios no dejará que se lleven todo y ahí está la ley también y también los compañeros de los grupos ecologistas y los muchachos de los colectivos que no ayudan a defendernos". Julián, empleado en una zapatería dice: "hasta la madre estamos con el mal gobierno y 
los empresarios que quieren hacerse más ricos. Se hacen uno uña y mugre juntos, el gobierno y estos de las empresas. La tierra no les importa quieren hacer sus minas y dejar despoblado el pueblo, quieren correr a la gente y la espantan y le ofrecen dinero por sus cosas, sus casas valen unos pesos según las cuentas que hacen. Dicen que la ley está con ellos y que el gobierno es parte de sus negocios ¿así quién puede contra ellos?, pero no está bien lo que hacen y menos a sus modos de patrones como en las otras antigüedades donde los mexicanos éramos puros indios sin escuela ni educación. Ahora ya son otros tiempos y no vamos a dejar que hagan sus planes de romper la tierra para hacer más agujeros y dejarla muerta para sacarle las cosas que tiene con sus minas". León dice: "a la tierra se le quiere y se defiende sola, por eso ya no llueve y caen las heladotas, ellos, los de las empresas ni mexicanos son, no pueden ser mexicanos si desprecian así la tierra con sus industrias son los que hacen esto, han resecado el alma de la tierra se marchita del agua sin ella". Roberta, albañil junto a su marido y madre de familia acusa: "los perros andan sueltos y están locos por quitarnos nuestro pedacito, en la casa no los dejamos entrar y les echamos los perros para correrlos, son como perros pero los de nosotros son más mejores, son buenos y amigos de nosotros". Jonathan, estudiante universitario hijo de campesinos dijo: "estamos aquí toda mi familia porque nos tumbaron la cosecha de maíz y los árboles y magueyes de la parcela para sacarnos de nuestro lugar que nos pertenece por herencia de mis abuelos. Ya hemos estado en otros lugares peleando por la justicia y los negociantes no van a ganar, ganaremos nosotros con la ayuda de los compañeros de los movimientos y de la asamblea de afectados y los otros amigos que están de parte nuestra y no nos han dejado solos. Sabemos que no estamos solos y que en todo el país hay gente que está con nosotros. Las empresas se irán y deben irse y la madre naturaleza regresará a nuestras manos, estamos dispuestos a conservarla". Homero, obrero de edad avanzada contestó: "desde hace años hemos trabajado en las fábricas, ahora quieren más, pero echan mucho veneno, ellos quieren hacer las industrias y están para tomar lo que es nuestro como si fuera de ellos, las empresas ensucian y nos avientan cochinadas, ni usamos lo que hacen. Teníamos el río y era muy fresquito, era de todos y nos daba agua para que no nos faltara, ya ni sirve, ahora ya lo ensuciaron y apesta, es donde ni queremos pasar, se acabaron el río y tenemos que buscar el agua más lejos y no es igual y apesta mucho y hay muchos mosquitos y las moscas sucias. ¿Adónde viviremos y dónde estarán nuestros hijos? Hasta los migrantes ya no quieren recibirlos los americanos. ¿Qué vamos a hacer?, pero ni qué hablar cuando vienen con sus campañas de candidatos y quieren darnos la misma canción de votar y votar, la democracia está muerta, bien fría". Damiana, señora madura dedicada a la venta de tortillas respondió: "yo entrego mis tortillas y gano unos centavos para mis hijos de la escuela de sus hijos pero cada vez puedo menos, la fuerza se me da menos y el campo me da menos, todo tan caro y apenas saco al gasto. A las viejas como yo las empresas no dan chamba pero eso sí, nos quitan todo lo que quieren, nadie los detiene, se están vaciando el país. Los americanos se están llevando el país para ellos ser ricos y matar al campo que les estorba para hacer sus ciudades, sus edificios grandotes con muchas calles y con pavimento pero ¿qué van a comer? El pavimento no se come, mejores son las tortillas de nosotros". Susana, joven que no estudia y tampoco 
tiene un trabajo remunerado nos señala: "yo vine porque me invitaron los muchachos del grupo, me han enseñado cosas de la política y a hacer adornitos para después venderlos aunque sea en la calle, también me han ayudado los muchachos sin cobrarnos para aprender a leer y escribir mejor, yo ya sabía pero otras gentes no y les van enseñando sin cobrar, hacen esto para ayudar a la gente. No me gustan las empresas que tratan a las gentes como animales ni las dejan trabajar ni las dejan comer su comida, ahí las tienen duro con el trabajo y les pagan bien poquito. No les alcanza y tienen que pasar muchos aprietos para comprar algo, por eso no trabajo ahora. Unas conocidas mejor se fueron al sexo para ganar dinero, ahí ganan más pero se vuelven malas y terminan enfermas y con hijos de hombres que ni saben que fueron sus hijos. No hay empresas buenas y nos dejan sin poder vivir en paz. Las empresas y sus dueños hacen que los jóvenes como yo se metan en el vicio y se hacen borrachos y mariguanos. Otras se hacen malas mujeres que trabajan en el sexo y les da vergüenza a sus papás pero dios las ha de perdonar porque son de fe".

\section{Sobre el futuro de sus familias:}

Sara, madre soltera de mediana edad nos responde: "estoy preocupada por lo que pasa en el país mientras el gobierno gasta tanto dinero en el bicentenario y fiestas que solo él quiso hacer, a mí nunca me preguntaron si quería gastar el dinero en esas fiestas, ya lo hicieron y el país sigue peor, nada cambió, muertos y mujeres violadas y gente sin trabajo o con malos trabajos que pudren a la gente. Yo no sé qué hacer ya que tengo mis hijos pero el gobierno no nos ayuda, nos quita muchos impuestos y sube las cosas siempre. Estamos a la mano de dios". Higinia, anciana ama de casa rural contestó: "el futuro ya no lo veo, ya no lo cuento ya voy de salida pero para mis familias sí, ellos no pueden perder lo poco que tenemos y que dios nos dio, ellos están aquí estamos juntos para oponernos a los que dicen que nos quieren joder. Que jodan primero a su madre. El futuro de ellos está en el infierno, serán castigados por dios bendito por ser malos hijos de la madre mayor de la naturaleza, del campo y de la madre de dios". Antonio, vendedor ambulante de frutas nos dice: "yo no pienso en el futuro, es más difícil, yo fui a la escuela y estudié pero solo puedo ahora vender mis frutas y sacar el día, vivo al puro día y me preocupa sacar el día, no puedo ver más lejos, necesito más estudiar para poder ver qué es el futuro. Soy de esta organización y siento que organizados somos más fuertes y nos defendemos más, tenemos un líder y nos aconseja, también están los "compas" de otros grupos que también ayudan a pensar y los de la universidad, unos maestros, doctores les dicen que saben mucho. En la organización queremos ser de democracias, los del gobierno no, puros votos, es un votadero del diablo". Nicolás, un pequeño abarrotero de edad mediana contestó: "el futuro solo es bueno para los ricos, ellos tienen todo hasta la vida larga que se operan del cuerpo para ser más jóvenes como si los años no les pasaran. Vemos en la televisión que el mundo se está acabando y mucha guerra de sangre y los criminales hacen sus cosas en todos lados sin miedo ya que el mismo gobierno los trata como buenos y les da protección por lana. Los políticos son iguales y ganan el dinero del pueblo sin tener que trabajar como uno, no veo a 
los políticos que estén flacos. Solo nos queda buscar el refugio de dios, él nos amparará en su casa". Petra, joven trabajadora en una fábrica señala: "miedo es lo que veo en el futuro, mucho miedo, tengo miedo de que me roben y me secuestren y desaparezcan mi cuerpo. No podemos confiar en las personas, parecen buenas, hablan bien, traen ropa buena y parecen buenas gentes pero uno no confía en ellas, si hasta los curas, dicen que le meten mano a una y abusan de los niños". Sofía, señora muy joven ama de casa con tres hijos declara: "la violencia nos mata, ahora debemos cuidarnos de todo y dentro de la misma casa. El gobierno no hace nada, solo miente para quedar bien delante de los extranjeros pero como no somos extranjeros ni caso nos hace. He visto como los grandes golpean a los chicos y los maridos a las mujeres, hay fuerte abuso. Yo pienso en mis hijos y no voy a tener más, los defiendo, ellos son el futuro para mí, a mi marido lo dejé y estoy en el colectivo social para ver por mis hijos, por eso me ve usted metida en esto aunque me haga vieja. Pero eso sí, que el pinche gobierno ni cuente con mi voto, no se lo doy, que vayan a chingar a otros más tontos, más vendidos que yo". Jacinto, de edad mediana conductor de vehículos públicos de pasajeros en la ciudad nos respondió: "la gente está mal, se ha ido haciendo más liberada pero más empeorada, yo los veo en mi trabajo y me doy cuenta de que vamos para mal, veo como se tratan y como tratan a sus niños y me da tristeza, como si no fueran sus hijos. Del futuro no sé qué contestar, yo creo que muchos estamos así. Cuando llego a la casa quiero ser mejor de lo que veo en todo el día en las calles para que mi gente tenga más futuro". Rosa, muchacha estudiante de nivel medio superior apunta: "el futuro es para los mexicanos, el futuro es para nosotros los que trabajamos y nos organizamos. El país es de los mexicanos y para los mexicanos, los extranjeros buenos pueden venir pero los malos deben quedarse afuera. El gobierno nos tiene que oír, nuestras luchas son justas y valientes hay mucha gente valiosa aquí y todos hacemos lo que podemos para que no nos destruyan con sus modernizaciones ni con su capitalismo. La escuela está bien pero será mejor si cuando los maestros sepan que igual que nosotros son mexicanos y su sabiduría está para servir a la población, ellos salieron de la misma, ahora deben hacer el futuro para las generaciones de más jóvenes que más muchos son". Edelmira, trabajadora de edad mediana de un taller de maquila de ropa nos contesta: "no sé jóvenes, no sé qué es el futuro no me lo imagino". Pascual, campesino y empleado en una fábrica señala: "se está acabando la tierra, ya no entendemos a la Madre, nuestra tierra es propia para trabajar pero no alcanza porque produce menos con los químicos que le echan. Anteriormente teníamos nuestras cositas del campo, yerbitas y frutas que se daban en el campo con la cosecha, ahora ya ni salen, el químico las mató. No, el futuro no se ve pero al día de hoy poco nos queda". Carmen, campesina de edad avanzada nos dice: "yo creo que dios es bueno y nos ayuda. Ahora nos va a ayudar, yo lo sé. Cuando mañana no tengamos qué comer ni el gobierno ni nadie nos va a dar, solo dios. El futuro es dios y es bendito, él es bueno y se acuerda de sus hijos. Nos dio la vida y la Madre Tierra y nosotros tenemos que guardarla, que quererla no como hacen ahora que todo lo contaminan y ni agradecen a la mamá más principal y tampoco al padre bendito del cielo, mi Señor". 


\section{Sobre el progreso y el desarrollo:}

Luis, estudiante en una escuela de capacitación para el trabajo nos responde: "para eso estudio, para progresar. Mis papás me dan la escuela y yo quiero ser alguien por eso no falto mucho. Casi siempre voy a la escuela y hago mis tareas. Quiero progresar". Benito, joven albañil soltero nos contestó: "no señor, no sé qué es el progreso ¿qué no es lo mismo? Otros dicen que es malo y otros me dicen que es bueno, no sé, deveras...". Plutarco, abogado en ejercicio y padre viudo, de edad mediana nos dice: "he aprendido en la universidad y en la vida que el progreso es cosa de la utopía, jamás está donde debe estar. El desarrollo es más o menos igual pero lo usan más ahora. Forma parte de los discursos de los gobernantes, de los políticos y de los de la academia. Creo que el desarrollo consiste en usar bien los recursos naturales para vivir mejor y para cuidar el medio ambiente". Ana, participante en una mesa de discusión de un foro nos dijo: "el progreso es el sueño del mundo. El desarrollo es la forma en que se da el progreso. Sin desarrollo no hay progreso. El progreso es más difícil de alcanzar que el desarrollo, se pueden desarrollar muchas cosas pero eso no es lo mismo que alcanzar el progreso. La gente tiene que progresar y tiene que hacerlo dialécticamente. El marxismo-leninismo sirve mucho para ver lo que es el progreso y el desarrollo, en México tenemos un poco de desarrollo pero no hay progreso". Paula, señora de edad avanzada, activista y miembro de un comité sindical nos respondió así: "la unión, la organización, el empoderamiento de la gente son el verdadero progreso. El desarrollo es un cuento gacho". Carmina, joven ama de casa sin trabajo remunerado nos dice: "esto que ve, esto que estamos haciendo ahorita es el progreso y también desarrollo, por eso dejé mis quehaceres para estar presente y participar en el movimiento. Vengo al plantón y regreso a la casa para llevar información a mi familia y vecinos. Yo hago el enlace entre ellos y los del movimiento. Así se progresa, así cuidamos juntos los problemas y así cuidamos a la casa más grande, al mundo con sus problemas y gentes ricas y nosotros pobres. Dicen los de los partidos y los de la política que si votamos hacemos progreso, que votando nos desarrollamos pero yo no creo". Heladia, habitante rural de edad madura dedicada a las artesanías nos dijo: "miren ustedes, siempre nos preguntan. Yo digo que desarrollarnos es estar bien y estar bien es cuidar lo que tenemos y no estarle pidiendo a la tierra más y más. La tierra es una Madre pero no puede darnos tanto, somos muchos hijos para una sola mamá, aunque sea grande. Si para progresar tenemos que quitarle a la Madre Tierra, eso no es progreso, lo digo y lo pienso así, gracias señores por venir conmigo a mi tierra y platicar, aquí está su pobre casa". Laura, joven enfermera soltera nos dice: "hemos progresado, no sé si nos hemos desarrollado, me confundo. El gobierno dice que estamos progresando mucho pero igual lo dicen en la televisión. Yo oigo el radio y en las noticias dicen seguido que vamos bien en el desarrollo del país que estamos progresando. Sin en cambio, yo no siento que estemos mejor. Mi trabajo apenas me da algo para irla pasando y así ni siquiera puedo pensar en tener una familia mía. Yo les preguntaría a todos: ¿esto es el progreso? Luego 
sacan que el mundo se está calentando y que los huracanes nos van a aplastar con inundaciones y todo eso que hemos visto como en Japón. Yo estoy en el colectivo porque así ayudo a otros y ellos me ayudan a mí. Creo que así se puede ir haciéndole para hacer el progreso y conservar la tierra de la contaminación tan fea, ¿no? Doña Tomasa es campesina y comerciante en pequeño, nos respondió: "para qué queremos progresar, estábamos antes bien, el progreso nos vino a chingar. Mire ahora, el pueblo está de puro polvo, vacío, la gente ya se fue. ¿De qué sirvió el progreso? Se llevaron a mis hijos y a mi marido, solas estamos muchas mujeres haciéndonos más viejas. Si regresan ya ni nos van a querer. Dicen que "Oportunidades" es para el desarrollo pero yo digo que chinguen a su madre, no tienen madre esos del gobierno con sus miserias, ni que no supiéramos trabajar. No están los hombres pero estamos las mujeres y estamos vivas. Somos amigas entre nosotros y participamos en la caravana para decirles que dejen de calentar a la tierra, que dejen su capitalista, que dejen a nuestros pueblos tranquilos, que dejen en paz a la madre tierra, nuestra mejor y madre mayora. No queremos más progreso, queremos vivir en nuestra patria chica con nuestros animales y con el campo que es nuestro. Un pedacito de tierra que dios nos dio y no lo vamos a perder. Con votaciones quieren engañarnos para siempre, ya aprendí, sí jóvenes, y mi voto es para mí". Hilario, campesino de edad madura nos dijo: "yo me fui con los americanos, trabajé muy duro y los americanos nos veían mal, nos trataban como criminales, como borrachos cagados. Me gané una enfermedad y ahora estoy aquí en mi tierra pero ya no puedo trabajar, me chingué. Me fui para progresar porque en México no hay progreso pero con los americanos tampoco, lo quieren linchar a uno, hasta presos estuvieron unos amigos solo por ser mexicanos prietos. El gobierno no hace nada por nosotros y nos tratan como perros con armas de la muerte para darnos balazos. No hay progreso. Yo no voy pero mis familias sí, están en la lucha con las organizaciones que luchan contra el mal gobierno que quiere vender al país sin luchar. Esos no son mexicanos todo les dan a los de fuera y nos quitan a nosotros. Ponen una fábrica y pagan sueldos de hambre que nadie puede vivir con eso. El Presidente del trabajo es puro lengua. Que se coma su progreso y que trabaje ahí él, la gente se enferma en ese puto trabajo".

\section{Sobre el estado de los elementos, factores y recursos naturales y otros:}

Anselma, señora madura ama de casa contesta: "yo viví en el campo pero nos tuvimos que venir a la ciudad porque no había trabajo ni buena escuela para los hijos. Cuando regresamos a ver el pueblo vemos que las cosas no han cambiado, están peor. Hay muchos pobres y se están acabando lo que queda del campo. Hay gente de la ciudad que ya no cabe y se van para el campo pero no saben que hacer ahí y no saben trabajar el campo, ya no hay magueyes ni árboles y el agua se está acabando, encima están muchas bandas de chamacos groseros que son drogados y ya ni creen en dios". Rita, adolescente estudiante de secundaria nos dijo: "me atrasé en mi escuela porque tengo que trabajar en el campo y en la casa, tengo que ayudar a mis papás. Todo está muy feo. No hay buen trabajo y en la escuela los compañeros son pesados y se pasan, atacan y atacan y quieren 
abusar de una, si no se defiende una le pasa lo que ya sabes, también los maestros. Junto a mi mamá estamos con el grupo para defender nuestras tierras. El gobierno con sus socios empresarios ricos quieren quedarse con nuestras casas y terrenos. Estamos combatiendo contra eso y me siento bien de no ser una dejada y mi familia tampoco. Si de por sí ya no hay buenas siembras ni buenos animalitos, si ya nos cobran de todo y nos cobran pasajes bien altos y nos ponen una carretera bien cara que no podemos pagar y nos echan su contaminación, entonces ¿cómo vamos estar bien? Los alimentos se acaban y la tierra se quiebra de tanto calor y ni gota de agua. La lluvia ya no cae como antes y llegan las granizadas y las heladas y nos termina todo el trabajo en la milpa, el temporal ya no es bueno, siento que dios nos olvidó". Aniceto, es un campesino de edad media, sin tierra y nos respondió: "¿pero cómo va estar? La verdad hace tiempo sacábamos buenas cosechas y el tiempo era más bueno. Sacábamos nuestros propios alimentos y no nos faltaba en todo el año. La tierra era buena, nos cuidaba y la cuidábamos, era de nuestra familia, éramos una familia con la tierra. Subieron los precios y perdimos nuestra tierra, ahora tengo que trabajar a jornal, la tierra ya no es mía pero la seguimos trabajando pero ya no da como antes. Ya no hay rastrojo ni majada para alimentarla y los químicos son muy caros y secan las venas de la tierra. Estamos sin protección, el gobierno no está y solo quiere elecciones para obligarnos a votar y hasta ahí llegan y ya se van. Ahora llueve muy raro y el agua de riego es para los que tiene arreglos. Los de las asambleas nos están ayudando son los únicos que no se han ido". Ángel, es un niño citadino que asiste a la escuela primaria pública, nos responde: "ya sé lo que son los recursos naturales, la naturaleza con la ecología y las contaminaciones, en la escuela vimos esto. También la maestra nos habló del cambio climático y mi hermana con unos compañeros se fueron a la marcha por el calentamiento en la Ibero (Universidad Iberoamericana). Mi mamá se enojó pero mi hermana de necia se fue con ellos. Dijeron que era peligroso porque el gobierno no los quiere ver". Tania, es otra niña citadina, estudiante del nivel básico, contestó: "mi mamá me enseña y me dice muchas cosas, me quedo con mi tía porque ella se va con los del cambio por el clima, sí, que están protestando aquí. Si sé lo que son los recursos naturales pero ahorita no me acuerdo porque tengo nervios por mi mamá. Ella dice que tenemos que pelear por nuestro derechos y tenemos que saber qué derechos tenemos por eso se va con ellos". Esteban, es un fontanero de edad mediana con tres hijos: "hago trabajos para las empresas, nos contratan con el arquitecto y nos pagan más o menos. Las obras son más caras pero no son mejores que antes, se les mete materiales más corrientes y las construcciones son muy chiquitas. La gente no sé como cabe ahí, parecen jaulas para animales y meten un montón de gentes ahí y tienen que pagar muy caro y años para pagar esas casitas que ni cimientos tienen. Yo no entiendo muy bien qué es la ecología, la naturaleza es la que nos da vida, le dicen que es la madre, pero no sé si somos recursos naturales nosotros. Oiga, estamos mis compañeros y yo en el curso y nos están dando clases para que veamos que la vida puede ser diferente y no vivir siempre en la pobreza con la televisión en la Chapoy esperando que el gobierno se acuerde de nosotros. Sí, estamos contentos con el curso y queremos más. A mi primo le quitaron su casa los del banco y así venimos a dar con los doctores de la universidad de México para que nos ayuden a saber defendernos. Sí, gracias". 
Celso, es un pintor-albañil de edad mediana, nos dijo: "no, la ecología es una cosa que no se sabe. Vi una revista en que tenemos que limpiar la ecología pero es caro, dicen". Celedonio, es un joven empleado en una tienda de abarrotes y contestó: "ya voy a terminar la primaria, estudio en la escuela para adultos. Sí, los recursos naturales se están terminando, ya no hay agua, ya no hay tierra, ya no hay comida natural, ahora todo es de compras, lo traen de otros países porque México ya no produce". Ixtli, es una joven indígena madre y campesina, nos dijo: "pero que ya casi no tenemos derecho a vivir. Siempre están contra los indígenas, nos dicen indios y nos ven como otros, distintos. Parece que les molesta que vivamos y trabajemos. La madre es la tierra, la Mamá Tierra. Así me enseñaron mis padres y yo soy feliz con mi pueblo y mi raza. La Madre Tierra es la que nos da pero no nos va a dar si la destruimos. El sistema de vivir depende de ella. Hay muchos recursos naturales pero se los quieren llevar lejos. Hasta el tiempo está diferente. ¿Qué vamos a hacer? Dijeron los profesores que somos un recurso nosotros los indígenas, un recurso de la cultura donde vive México de los mexicanos, todos nosotros". Rufino, señor indígena entrado en años nos dijo: "luchamos desde hace años, no nos vamos a dejar quitar nuestros recursos. Somos indígenas pero también valemos como los de la ciudad. Acá la ecología no anda muy bien, joven, ya se llevaron tanto. La naturaleza ahora sufre. El hombre no la quiere y la desperdicia. Nosotros somos afectados ambientales y sabemos, porque nos han dicho, que los recursos naturales se están acabando pero sabemos igual que la tierra sufre por lo que le han quitado a la madre, santa madre de tierra, la mera mamá. Tenemos años de andar peleando pero no nos vencerán, seguiremos luchando, cueste lo que cueste. Tenemos que dar la cara a los ricos que se unen al gobierno para despojarnos. No vamos a dejar que pasen. No queremos más destrucción en el campo. Que la ciudad se las arregle ella misma. Que les compren a los gringos".

Durante los "encuentros" que se han celebrado y puesto que se realizan cualquier día de la semana, es común que se hallen personas alrededor que no son participantes, que no fueron convocadas, que viven y/o trabajan en lugares cercanos a los sitios donde se verifican los mismos o bien personas que se encuentran ahí solo por coincidencia; para complementar nuestra información también se ha entrevistado a algunas de ellas y en seguida aparecen unos ejemplos de lo que exponen.

Doña Guadalupe nos dice: "no sabía que estaban estás pláticas pero veo que hay mucha gente descontenta pero faltan más, habemos muchos descontentos con el gobierno y yo estoy descontenta también, a mi hija la despidieron solo porque se embarazó de su esposo, ellos son casados". Hugo, joven vendedor ambulante de ropa de segunda mano comenta: "yo no me enteré de la marcha pero ya me di cuenta de por dónde andan, ahorita estoy chambeando en el mercado pero si no, me juntaba con ustedes, hay que protestar y pedir que cumplan, ya que dejen de robarnos, son unos rateros esos del gobierno ni pena les da pedir nuestros votos, sinvergüenzas". Gabriel, dueño de un taller mecánico apunta: "siempre están los que protestan, siempre, todos los días se ve así las calles, no dejan en paz, estos desfiles (marchas) ya no son para ahora, ya nadie les hace caso, hacen un desmadre con las calles y no se puede trabajar. Que vayan con el gobierno, aquí 
no es su lugar". Jesús, un señor joven con cuatro hijos y empleado en una tienda por departamentos dice: "qué lata, qué lata dan, creen que el zócalo es suyo y se ponen ahí para molestar. Ni ganas dan de venir al centro, para qué, nomás para ver puros desfiguros, que si ya no les pagan, que si ya los corrieron, que si les deben harto, que si ya se van a morir de hambre porque están en huelga de hambre, pues que coman, que no sean zonzos, qué piensan, que así nomás les van a dar dinero, están tontos estos. Tanta gente y se quieren morir de hambre ¿qué no piensan? Francisco, maestro de primaria entrado en años nos dijo: "ya en la televisión dijeron que el gobierno no dará un paso atrás, las carreteras son para progresar y la gente tiene que entender que si les quitan su casa por la carretera, así es la decisión del gobierno y es para que estemos mejor todos. Yo sé que de todos modos la gente pelea pero no hay que pelear, ya lo decidieron y como en el D. F., o se componen o se los lleva el tren. Pusimos al gobierno para obedecerlo, ahora que se aguanten". Guadalupe, un señor de mediana edad obrero textil nos comenta: "a mí me quitaron un cacho de terreno donde sembrábamos y nos dieron un dinero. No entiendo por qué hacen tanto problema de que el agua ya no está buena y el río hiede. Yo compro mi agua y la vamos pasando. Está buena, más buena que el agua de antes, ahora hasta la consigue uno en botellas o con garrafas. ¿Por qué hacen tanto escándalo? El río de todos modos no era de nadie y los terrenos del río tampoco, son de la nación. No se perdió nada". Herminia, ama de casa de mediana edad dedicada a la costura en su domicilio, nos dijo: "nos invitaron a los talleres y las pláticas pero no quise ir, ahora están aquí frente a mi casa y no me gusta que vengan y ensucien toda la colonia. Mucha ecología de los ecologistas pero dejan ahí sus suciedades. Dizque hay que reciclar y apagar la luz pero ellos no nos dan nada, todo quieren que lleve uno, por eso no voy, mejor trabajo, ellos no me dan nada y no dejo que mis hijos se les acerquen". Antonia, mujer campesina de edad indeterminada comentó: "sí, hace tiempo que los de aquí están en contra de las torres de la luz, dicen que son malas porque hacen daño al cuerpo y al cerebro, que endurecen la sangre, dicen. Yo no lo sé, me lo dijeron. Yo no los apoyo porque no sé, vaya a ser cosa de los partidos y la llevan a uno al baile sin saber nada. Las torres nos dan la luz, si las quitan no tenemos luz. Yo no los quiero más cerquita, no me dan confianza. Yo pago poco de luz, tengo unos poquitos focos nomás...". Dulce, estudiante de bachillerato responde: "en el Internet yo he visto que hay mucha violencia, hay muchachas que desaparecen y luego están ahí tiradas hasta sin cabeza. Luego en las noticias dicen que son mujeres de la calle, o sea, prostitutas y con eso se la quitan. El país está mal y no veo la manera de que se componga. No creo en el gobierno y el futuro está en chino para mí. Voy a pensar muy bien antes de embarazarme, no tengo qué darle a mis hijos, ni casa tenemos". Alma, estudiante universitaria nos comentó: "en la uni estamos siendo capacitados para defendernos de los asaltantes y violadores, ya sé defenderme estoy estudiando artes marciales. Yo participo en un grupo de teatro que va enseñando a la gente a vivir mejor. Hacemos obras gratis y nos divertimos. Llevamos cosas y ponemos música y la gente se pone contenta y nos pregunta muchas cosas. Yo apoyo estos movimientos populares del verdadero pueblo, cuando termine la escuela me voy a meter en alguna organización más grande". Rómulo, joven desempleado y sin estudios nos comenta: "ya basta, ya basta de tanta tranza. Los diputados más 
gordos, vean a ese gordo del gobierno en la tele, da asco. Quieren que votemos por sus candidatos y nos traen puras madres para convencernos y comprar los votos pero mienten siempre. Yo les aviento sus porquerías y mis cuates. Nada de trabajo y en las escuelas no enseñan. Mejor voy a ver si me voy para el otro lado, allá están unos familiares y a lo mejor ya no regreso". Ángela, joven ama de casa dice: "los protestantes estorban, hacen mucho ruido pero estoy con ellos, si tuviera tiempo los acompañaba, es justo lo que piden, hay que defender a nuestro país, al planeta, la tierra es".

Estos son ejemplos de lo expresado por nuestros entrevistados, por un lado gente afectada directamente por toda una larga y diversa lista de problemas socioambientales y por otro lado, gente "simplemente" habitante del México de nuestros días. Veamos ahora, en un sucinto recorrido, otras expresiones verificadas en distintas luchas por todo el territorio mexicano donde son los mismos protagonistas de tales luchas y participantes de diferentes "eventosencuentros" y movimientos los que aportan sus voces; solamente los retomamos de las fuentes en que fueron publicadas. Con esto intentaremos "completar" nuestra presentación haciendo las veces de un referente "comparativo" entre lo expresado por nuestros directamente entrevistados y los señalamientos de estas últimas personas abriendo la situación a ítems diversos, donde no cuesta demasiado esfuerzo percibir el paralelismo entre unos y otros, todo ello ubicado en nuestro país pero en amplios nexos con muchos otros países y momentos, incluso de años más atrás debido a que este tipo de problemas y luchas son duraderas y algunas continúan hasta nuestros días.

Una participante en la sexta Asamblea Nacional de Afectados Ambientales verificada en Magdalena Ocotlán, Oaxaca señala sobre la COP-16: La ruta a Cancún sólo es un momento en la lucha... la asamblea aprueba avanzar más allá de Cancún con La Vía Campesina para lograr cambios en contra de la destrucción ambiental y para mejorar las condiciones de nuestro planeta (Sexta Asamblea Nacional de Afectados Ambientales, 2010). H. Bellinghausen dice: Gobiernos militarizados y delirantes en lo interno, y arrodillados en lo externo, histéricamente trenzados con las mafias, como los de Colombia y México, creen que podrán acabar con los pueblos que se les atraviesen (La Jornada, 2010). El mismo Bellinghausen apunta: La palabra recuperó su condición de verdad que la práctica política le había arrebatado en México. Y así como su voz es un arma, un escudo, una fuente, los zapatistas también han enseñado el significado del silencio (La Jornada, 2010). Por su parte S. Ribeiro establece: ... hay otras leyes e iniciativas de ley y muchas otras normativas y programas de gobierno. Cada una tiene aspectos negativos, pero lo más preocupante es el paquete general que conforman, que constituye una tremenda agresión y la legislación del despojo no sólo a los pueblos indios, sino también a campesinos, trabajadores, jóvenes, jubilados y muchos otros sectores de la base nacional (La Jornada, 2005). Los indígenas huicholes dicen: Que nos devuelvan lo que en justicia es nuestro y que nos dejen seguir cuidando nuestra casa de acuerdo con la palabra antigua, la de nuestros padres y abuelos. Escuchen, sean valientes, acaten la justicia, sólo si seguimos ese camino con nosotros los indios, con la naturaleza y con todo, 
podremos decir que tenemos Dios, que somos buenos (Asambleas wixárika, 1996).

Ignacio del Valle, líder de la lucha en San Salvador Atenco, Edo.-Méx. dice: Lucho ahora por él (su hijo) también y porque somos gente que no nos gusta la injusticia. Y agrega: Aquí nadie se cansa. Nunca has visto a esta gente enfurecida. Somos nosotros los que los calmamos... (Mejía, 2007). Jerónimo, dueño de una fábrica comenta: Somos mil personas y en tres años, hemos sufrido casi cuatro mil asaltos. Yo llevo siete asaltos (Mejía, 2007). En Oaxaca, dentro de las luchas de la APPO (Asamblea Popular de los Pueblos de Oaxaca) de amplia repercusión nacional, una persona anónima sentenció: Si hay que morirse por esta tierra, pues así viene la cosa (Mejía, 2007). H. Rodríguez (2006) establece: (...) Pero también los conflictos locales se han multiplicado por la creciente conciencia ambiental, por el despertar ciudadano que ya no tolera la corrupción, por el influjo de las luchas por los derechos humanos. Una persona anónima dijo: Mi abuela que hablaba náhuatl nos recomendó de dejar una parte del arbolado alrededor de los manantiales. En ese preciso lugar denominado Quivisquihuapan, se derribaron varios árboles provocando el enojo profundo que representaba la invasión de los poderosos, políticos, a la familia de origen indígena sin ninguna orden legal (Boege, 2006). M. Molina, en esos momentos delegado estatal de la Semarnat, adujo que "La Joyita" no es más que un viejo y abandonado cafetal, que si se construye sobre él un Wal Mart, no se viola ninguna norma. Bajo esta premisa, no tendríamos razón para preocuparnos, nos libramos de la tarea para cuantificar lo invaluable de lo intangible que representan los servicios ambientales que esos árboles prestan a la ciudad de Xalapa (Moncada, 2006). A. Barreda (2006) anota: El peor problema de la actual crisis del agua es la forma en que las empresas trasnacionales, gobiernos e instituciones pretenden resolverla.

¡Ni una muerta más! ¡Justicia para las mujeres de Juárez! Cerca de un millar de personas se manifiestan por las calles de Ciudad Juárez a finales de abril de 2005. Con la presencia de numerosos activistas de Latinoamérica pero sin la de las autoridades locales ni estatales se desarrolló la marcha. La presidenta de la Comisión de Investigación Parlamentaria sobre los Asesinatos de Mujeres de Ciudad Juárez declaraba ahí: Lo deploro, pero esto prueba suficientemente lo que piensan del dolor de las familias (Fernández y Rampal, 2006). En ésta misma fuente, J. Fonda, la famosa actriz y activista sostenía, durante una marcha hacia Ciudad Juárez: Yo soy blanca, soy conocida, yo soy rica. Tengo una hija, tengo una nieta y sé que si una de ellas desapareciera, la policía haría todo lo posible por encontrarla. En otro caso y lugar, el 7 de mayo de 2004 la Semarnat modificó discrecionalmente la NOM-022 referente a la protección de humedales costeros. Greenpeace y el Centro Mexicano de Derecho Ambiental atribuyeron la modificación a presiones de los desarrolladores turísticos de Cancún. El director de Greenpeace-México adujo: (...) la norma fue modificada para que quienes destruyeran este ecosistema ya no fueran delincuentes ambientales, sino simplemente tuvieran que arreglarse con los funcionarios de la Semarnat. $Y$ agregaba: Se trata de una lógica perversa que en los hechos significa que nuestros recursos pueden ser destruidos siempre y cuando se pague por ellos. $Y$ una vez que están destruidos, ¿qué se va a proteger? Es aberrante que la propia 
Semarnat haya argumentado motivos económicos para permitir la destrucción de uno de los ecosistemas más importantes y frágiles de nuestro país (Palma, 2006).

Terminando este breve repaso anotaremos lo siguiente, tomado de Barreda (2006): F. Hernández decía: En México, realmente tenemos un problema con el agua. Escuchamos continuamente que nos acercamos a una crisis del agua: nos lo dicen desde todas las esferas del gobierno federal, estatal y municipal, y sin embargo no nos dicen por qué. J. Castillo indicaba: La política que se ha aplicado en nuestro país, en materia agrícola, en materia hidráulica, siempre ha perjudicado mayormente a los campesinos y a los indígenas. Todas las modificaciones que se hicieron a la Ley de Aguas Nacionales a quienes más perjudica directamente es a nosotros. F. Flores de La Parota, Guerrero sostuvo: En la actualidad, los gobiernos federal, estatal y municipal han pretendido hacer una presa en Cacahuatepec sin que a los campesinos, comuneros y ejidatarios los hayan tomado en cuenta. Ahora viene la represión en contra de nosotros, ya que para los gobiernos es un delito defender la tierra, la cuenca del río Papagayo. D. Ortega de Chiltoyac, Jalapa, Veracruz aseveró: El ayuntamiento de Jalapa compró 12 hectáreas, las deforestó totalmente para construir un relleno sanitario que yo llamo tiradero a cielo abierto, y lo instaló encima de una cabeza de cuenca, donde hay mantos acuíferos. J. Lara de San Sebastián Teponahuaxtlán, Jalisco afirmaba: Desde hace algunos años se construyó la presa Agua Milpa y nuestros hermanos wixaritari de Nayarit, hermanos huicholes, fueron agredidos en sus terrenos, les indemnizaron a bajo precio, más de 20 familias se desplazaron a otros lugares y enterraron terriblemente un lugar sagrado para los wixaritari de esa zona. G. Palma y F. Palma comunicaron: Venimos del Estado de Chihuahua, nosotros somos rarámuris, nos conocen como tarahumaras..., (...) El proceso de privatización del agua ya lleva más tiempo allá. (...) Llegaron los blancos y nos corrieron a la sierra. Ahora vivimos en la sierra donde hay pinos pero también ya llegaron ellos ahí. Lo que hicieron fue cercar los territorios donde había agua, entonces nosotros ya no podíamos pasar por nuestras veredas, nuestros caminos. Cercaron todos esos lugares y nuestros animales ya no pueden beber agua de ahí... En realidad hay muchos testimonios más pero pensamos que es suficiente con lo hasta aquí anotado, revalorando estas voces-eco populares que se suman, todas ellas, a las ya publicadas antes por nosotros mismos para un caso de lucha específico en Puebla-Tlaxcala, México (Lara, 2011). Ahora daremos paso a una corta discusión sobre nuestro tema.

Se puede pensar que a pesar del proceso mundial de estupidización del ser humano por medio del desarrollo del socialconformismo (Roitman, 2003), proyecto abierto, sostenido en el tiempo y mantenido por el sistema de dominio hegemónico de los poderosos, mucha gente todavía no se ha visto vencida por semejante monstruo e intenta continuar su vida como va pudiendo y en otras ocasiones lucha contra el leviatán modernizador que instala a la gente en máquinas devoradoras de seres humanos y conciencias, máquinas que consumen tanto a la gente como a los elementos naturales y está agotando a los ecosistemas sin respeto ni cuidado alguno por la naturaleza, nuestra casa y único hábitat con el que contamos los seres humanos. A cambio la tecnociencia más presuntuosa mejor se dedica a invertir millones de dólares para que en "el proyecto más grandioso de la 
humanidad", unos cuantos "elegidos-privilegiados" pudieran habitar el planeta Marte (como ejemplo), ya que nuestra Madre Tierra se está acabando mientras llevan al mayor deterioro a toda la biosfera y con ella a los sistemas humanos.

La gente todavía respira y sigue pensando, también actúa se organiza y resiste (haciendo eco de la resistencia, 2000, aconsejada por el recién fallecido Ernesto Sabato) los embates severos del sistema geopolítico y económico mundial establecido que transforma a la vida en una mera mercancía más en el mercado hecho sistema y fuente de todo, al lado de la educación, la conciencia, la dignidad, el conocimiento, los saberes y el propio dinero convertidos también en mercaderías en compra-venta y alquiler al mejor postor-inversor.

El mundo de la modernidad-posmodernidad que nos tocó testificar y testar es ampliamente contrastante, así igual se da a las tareas de asegurar la máxima comodidad y confort para la gente que pueda pagárselos que lo hace directamente sobre la explotación salvaje tanto de los elementos y factores ecosistémicos así como directa-indirectamente de millones de seres humanos sumiéndolos en sistemas de producción y reproducción ajenos a las reglas y normas más humanas y también de las naturales, bajo sistemas de opresión de amplia injusticia ambiental con condiciones de trabajo que son nuevas formas de esclavitud y al mismo tiempo, llevando a millones de personas a la pobrezamiseria distanciando las posibilidades de formas de vida más conectadas con la sustentabilidad (Lara, 2007).

El modelo neoliberal o del capitalismo salvaje que impera alrededor de todo el globo va despojando a las personas de sus patrimonios físicos, intelectuales y emocionales, pero igualmente ha ido deteriorando el entendimiento entre los humanos y entre los humanos y el resto de la naturaleza (re-anotando nosotros, que el ser humano es parte de la naturaleza y que la naturaleza habita dentro del mismo ser humano; Lara, 2010).

Mediante el proceso de apropiación de los humanos no poderosos y de los elementos-factores que integran a la naturaleza para hacerlos y manipularlos como "recursos", unos "recursos naturales" y otros "recursos sociales" o "recursos culturales" en una visión economicista ambiciosa que los resume (y consume) a ambos como "materias primas" (además desechables y sumamente sustituibles en el momento y sitio que le convengan al sistema opresor hegemónico), son mutados a "simple" "capital natural" los primeros y a "capital social o capital cultural" los segundos en un modo de concebir irrestrictamente al todo existente en nuestro planeta (por supuesto, incluyendo la vida misma) como "material usable y disponible" para sostener al sistema agotador y antinatural en marcha hasta que el mundo dé de sí en un trastocamiento de las bases ecológicas al no reconocer lo que la ecología y sus valores e importancia son (Araújo, 2004).

Pero hay personas que han logrado mantener su estatus de seres humanos, de personas humanas en medio del caos violento e inestable fraguado por el sistema. La conciencia más humanizada, más ambientalizada no ha sido borrada, eliminada, ni tan solo olvidada pese a los fuertes esfuerzos permanentes aplicados con fanatismo por el sistema y sostienen posiciones opuestas al movimiento que 
nos está llevando a la devastación ecológica y a la erosión de la persona humana, los individuos, los colectivos, las comunidades y las sociedades. Estas personas constituyen la esperanza de hacer una vida distinta y de distinta manera a la impuesta hoy mediante los modelos de desarrollo aplicados hasta el momento en la inalcanzada "conquista" del progreso, anunciada como el destino único de la humanidad y del mundo pero que, como señala Schils (2008) implica el ejercicio del neoliberalismo y por tanto del consumismo.

En todo el orbe hay individuos y grupos que se oponen al proceso de deterioro que se ha constituido en un (casi)sistema y estado de crisis consumidor de los recursos naturales aproximando su agotamiento; siendo en México la ganadería y el sector petrolero las actividades que por recibir mayor gasto exógeno son las actividades que dan un más alto costo de agotamiento (González y colaboradores, 2008). Hay personas que individualmente están en contra de dar continuidad a tan nefasto proceso antinatural y se mantienen al margen de las tendencias mayores, quizás esperando mejores tiempos o circunstancias $y$, tal vez recurriendo a sus creencias y fe religiosas o de otras índoles donde igualmente se ha perseguido históricamente alguna definición (Beyer, 2006). También hay personas que en lo individual sostienen una lucha desigual contra el leviatán capitalista destructor, pero asimismo existen las personas que se han organizado y se están organizando para dar la lucha por la conservación y preservación de la vida, de las sociedades, de los derechos civiles y humanos, del rescate de la naturaleza y de sus propias culturas, para darle a nuestro planeta una nueva oportunidad en la diversidad tanto biológica como cultural donde los procesos evolutivos sean más los de corte natural y no los impuestos por los intereses del poder capitalista (Araújo, 2004), esquilmante, que viola y ha violado la evolución natural desde tiempo atrás y con el poder de la tecnociencia más "de punta", de "última generación" está intentando acopiarse de las capacidades para hacer una temible realidad el manejo de la vida para decidir sobre las especies y, alcanzar en la cima de sus anhelos de dominio (que socioambientalmente hablando es más bien una sima, es decir un profundo, oscuro y desconocido abismo-precipicio) la "fabricación" de seres humanos "al gusto del cliente", "a gusto para el sistema" haciendo uso indebido de la genética y dándose así, el "derecho" a "fabricar" personas y otros seres según las conveniencias del momento y de acuerdo a los dictados del "sagrado e inviolable-inmutable-incuestionable" mercado global.

Las luchas, como sabemos (Martínez Alier, 2007; Vargas, 2006), han sido duras en todo el mundo, se ha buscado la hoy denominada justicia ambiental (Vargas, 2006). Pueden contarse numerosos muertos, heridos, desaparecidos, encarcelados, enjuiciados, perjudicados en general, pero los afectados ambientales alrededor del planeta son muchos más; resulta bastante difícil encontrar así como determinar qué persona o qué familia no ha sido afectada por el sistema, por supuesto que los beneficiados por el sistema destructor existen, sin embargo son unos cuantos: una minoría increíblemente reducida y más cuando se le compara con las grandes mayorías afectadas por la fenomenología capitalista recrudecida por su asociación con los gobiernos débiles de los países comparsa dependientes ampliamente de las directrices de la "máquina devoradora" inhumana. 
En nuestro país, las luchas y los luchadores mexicanos acompañados de personas y grupos extranjeros se están reproduciendo con celeridad dado el nivel de deterioro de las condiciones de vida y el desgaste significativo de los ecosistemas, junto a los inmorales golpes de la violencia del crimen organizado asociados a la criminalidad "no organizada" que ha ido alcanzando topes más altos cada día, alimentados y retroalimentados por el capitalismo expansionista deliberado. Con gobernantes (de todos los niveles de gubernatura) que declaran una y otra vez la "bonanza" de los manejos económicos del país y el "avance" de los "beneficios" sociales y, con un sistema de partidos políticos que no lo es (que más bien es un caótico conjunto de allegados defensores de intereses personales y acaso grupales, en general con vasta carencia de principios y valores humanos y civiles, así como una "mezcolanza" explosiva de pasiones hasta fanáticas basadas en elevados niveles de ignorancia, rencores, rencillas, venganzas, prejuicios y desvalores, todo ello ofertado a la grosera y vulgar búsqueda del poder por los medios que sean, legales o no, legítimos o no), el país mexicano se encuentra en una condición harto semejante a la dada durante el Porfiriato; dictadura de 33 años que desencadenó en la Revolución Mexicana de 1910 (von Wobeser, 2010). Como termina señalando Jasso (2010): En la primera década del siglo XXI observamos que es precisamente esta expansión capitalista, en su fase de globalización, la que igualmente ha provocado la organización y lucha contra el sistema inequitativo y centralizado en el que se cimienta.

Un siglo después nuestro país no brilla por su "desarrollo" y menos en los términos rurales, agrícolas y agrarios; como indican Ortega y colaboradores (2010): El mediocre desempeño de nuestro país, y el magro crecimiento de la producción agrícola, se debe en gran medida a la aplicación de lo que se denomina como políticas neoliberales.

\section{Conclusiones}

México no es un país industrializado como quisieron forzarlo por décadas, no es un país de economía rica, no es un lugar donde se dé la justicia, la equidad, la igualdad, la libertad ni la democracia. La democracia es una de las apariencias y para ocultar su alta carencia. Se entiende por democracia casi exclusivamente el ejercicio del voto en las perpetuas elecciones de los supuestos "representantes del pueblo". Elecciones que son demasiado caras en lo económico y socioambiental, elecciones donde no hay de dónde elegir.

Delante de esta visión panorámica de un país sometido por los designios del sistema del poder, los individuos y los colectivos se han ido construyendo para: darse a la defensa de los golpes repetidos y sostenidos que impactan y desangran a las sociedades y al resto de los componentes ecosistémicos que bloquean las posibilidades más concretas de los procesos de sustentabilidad. Para plantear y demostrar que otra forma de vivir juntos es posible, que el capitalismo y las modernizaciones no son la única ni la mejor manera de convivir ni evolucionar. Para sostener ambientalmente el desempeño humano en sana coparticipación con el resto de la naturaleza. Para mostrar y demostrar que las leyes humanas no 
están por encima de las leyes de la naturaleza y que es el ser humano el que debe ceñirse a las reglas naturales no la naturaleza a las reglas humanas y menos a las del hipercapitalismo vigente.

Con grandes restricciones y problemas y enfrentando amenazas y severos riesgos hay gente en México que está organizándose e intenta organizar a otros para dar la lucha contra la injusticia ambiental manifiesta a lo largo y ancho del territorio nacional (con sus conexiones internacionales y mundiales), para aspirar cuando menos a reducir el caos y las violencias y buscar los medios más humanizados que obren una vida de mejor calidad para la población con un respeto hacia los demás componentes del medio natural extrahumano. Para renovar el contrato social y para renovar la necesaria fusión humanidad-naturaleza hoy hecha una verdadera fisión y ficción, aladas, ambas en las poderosas extremidades de la electrónica, la computación, la informática y las comunicaciones que han impuesto el ritmo de los quehaceres, maquinizando-digitalizando-programando las vidas de todos los seres.

Las voces que hemos querido hacer más públicas por este respetable medio pueden seguir siendo desoídas por el sistema, pero bien sabemos que muchas otras personas las están escuchando y generan con ellas un nuevo eco de dignidad individual y colectiva solidificada por la misma solidaridad que el espíritu humano glocal va inyectando a los movimientos en pro de la vida, de la vida de calidad, humanizada-ambientalizada que crea nuevas condiciones para la esperanza de un pronto amanecer en el que la luz solar sea tan gratuita como siempre lo ha sido, restándole posiciones y posibilidades al sistema expoliativo de que un mal día nos vendan un rayo de sol enlatado. Lo que dice, un mundo y una vida más sustentables directamente emparentados con la revivificación de la Madre Tierra Pachamama, la que es madre de todos, de nuestra gente, de la gente viva, donde se encuentra y elabora el propio ambiente, más popularizado como "medio ambiente".

\section{Bibliografía}

Araújo, J. 2004. La Ecología. Maeva. España.

Asamblea Nacional de Afectados Ambientales (sexta). Revista Biodiversidad, sustento y culturas. No. 66, 2010. Editada en varios países de América Latina.

Asambleas wixárika. 1996. Documento de las asambleas wixárika a la Consulta sobre Derechos y Cultura Indígena. Nueva Colonia. Mezquitic. Jalisco. México.

Barreda, A. 2006. ¿Crisis del agua? Revista El Jarocho Verde. No. 1. Nueva Época. Xalapa. México.

Barreda, A. 2006. (Coordinador). Voces del agua. Privatización o gestión colectiva: Respuestas a la crisis capitalista del agua. Testimonios, experiencias y reflexiones. Itaca. México. 
Bellinghausen, H. 2010. Gracias a los zapatistas. Diario La Jornada. 17 de mayo. México.

Bellinghausen, H. 2010. Sin pueblos indígenas no hay nación. Diario La Jornada. 14 de junio. México.

Beyer, P. 2006. Definir la religión desde una perspectiva internacional: Identidad y diferencia en las concepciones oficiales. Revista Alteridades. Vol. 16. No. 32. AUM-I. México.

Boege, E. 2006. El caso del libramiento de Xalapa. La construcción de ciudadanía ante obras públicas de gran envergadura. Revista El Jarocho Verde. No. 1. Nueva Época. Xalapa. México.

Fernández, M. y J.-C. Rampal. 2006. La ciudad de las muertas. Indiferencia política, ineptitud oficial, indignación mundial y los asesinatos siguen. Grijalbo. México.

González A., R.; J. Matus G. y M. González G. 2008. Efecto de las políticas económicas en los recursos naturales y el medio ambiente en México. Agrociencia. Vol. 42. No. 7. Colegio de Postgraduados. Texcoco. México.

Jasso M., I. J. 2010. Las demandas agrarias en el discurso de las organizaciones purépechas de Michoacán: Problemas sin resolver. Revista Ra Ximhai. Vol. 6. No. 2. Universidad Autónoma Indígena de México. Sinaloa. México.

Klare, M. T. 2003. Guerra por los recursos. El futuro escenario del conflicto global. Urano. España.

Lara G., J. D. 2007. Modernidad, posmodernidad y sustentabilidad. Revista Elementos. No. 66. B. Universidad Autónoma de Puebla. México.

Lara G., J. D. 2010. La confrontación falaz humanidad-naturaleza. Revista La Ciencia y el Hombre. Volumen XXII. No. 2. Universidad Veracruzana. México.

Lara G., J. D. 2011. Gobiernos precarios. Afectados ambientales en PueblaTlaxcala (México): Reflexión y breve relatoría. Revista Nómadas. 29. (I). Universidad Complutense de Madrid. España.

Martínez A., J. 2007. El ecologismo popular. Revista Ecosistemas. Vol. XVI. No. 3. Asociación Española de Ecología Terrestre. Alicante. España.

Mejía M., F. 2007. Salida de emergencia. Mondadori. México.

Moncada, E. 2006. El tesoro de La Joyita. Revista El Jarocho Verde. No. 1. Nueva Época. Xalapa. México.

Ortega H., A.; M. León A. y B. Ramírez V. 2010. Agricultura y crisis en México: Treinta años de políticas económicas neoliberales. Revista Ra Ximhai. Vol. 6. No. 3. Universidad Autónoma Indígena de México. Sinaloa. México.

Palma, G. 2006. Revelaciones del desastre. La negligencia y la corrupción que el huracán Wilma puso al desnudo. Grijalbo. México.

Ribeiro, S. 2005. Letra muerta. Ojarasca 99. Diario La Jornada. Julio. México. 
Rodríguez, H. 2006. Conflictos ambientales en Veracruz. Revista El Jarocho Verde. No. 1. Nueva Época. Xalapa. México.

Roitman R., M. 2003. El pensamiento sistémico. Los orígenes del socialconformismo. Siglo XXI/UNAM. México.

Sabato, E. 2000. La Resistencia. Planeta/Seix Barral. Buenos Aires.

Sartori, G. 2007. Homo videns. La sociedad teledirigida. Punto de Lectura. España.

Schils, L. 2008. Una teoría postcolonial de México, Wal-Mart y la idea de progreso. La invasión de los wal-marcianos. Revista Espiral. No. 41. Universidad de Guadalajara. México.

Torres C., G. 2006. Poscivilización: Guerra y Ruralidad. UACh/Plaza y Valdés. México.

Vargas H., J. G. 2006. Nuevos movimientos sociales ambientales en México. Revista Venezolana de Ciencias Sociales. Vol. 10. No. 1. Universidad Nacional Experimental Rafael María Baralt. Cabimas. Venezuela.

Wobeser, G. (von). (Coordinadora). 2010. Historia de México. FCE/SEP/Academia Mexicana de Historia. México.

*José David Lara González es ingeniero civil. Mexicano de nacimiento. Tiene estudios de maestría en hidrología subterránea y, también de maestría en ciencias ambientales en el área de ambiente y recursos naturales. Actualmente es candidato a doctor en ciencias ambientales en el área de desarrollo sustentable y ambiente. Es profesor-investigador universitario de tiempo completo con un desempeño mayor a 25 años. Ha trabajado en proyectos de evaluación, uso, manejo y conservación de recursos naturales con énfasis en los recursos suelo y agua y, en investigaciones en el área de la educación ambiental con acento en la divulgación-difusión de la problemática socioambiental. Ha publicado ensayos y artículos en revistas nacionales e internacionales de ciencias, ciencias sociales, educación, cultura y filosofía. 